\title{
Christian Wenzel Art and Imagination in Mathematics
}

\section{Discovery or Invention?}

In the chapter "Deduction of Pure Aesthetic Judgments" from his Third Critique, Kant develops a theory of genius (sections $45-50$ ) which leads him to the claim that there can be genius in the arts but not in the sciences. For instance in section 47 he argues that someone like Newton can be called "a great mind" (ein großer Kopf) but should not be called a "genius" (Genie). The reason he gives for this is that everything Newton has discovered can be learned, whereas one cannot learn how to write poetry. Newton can show us step by step what he has done, but Homer and Wieland cannot. Kant writes:

\begin{abstract}
Thus everything that Newton expounded in his immortal work on the principles of natural philosophy, no matter how great a mind it took to discover it, can still be learned; but one cannot learn to write inspired poetry, however exhaustive all the rules for the art of poetry and however excellent the models for it may be. The reason is that Newton could make all the steps that he had to take, from the first elements of geometry to his great and profound discoveries, entirely intuitive not only to himself but also to everyone else, and thus set them out for posterity quite determinately; but no Homer or Wieland can indicate how his ideas, which are fantastic and yet at the same time rich in thought, arise and come together in his head, because he himself does not know it and thus cannot teach it to anyone else either. In the scientific sphere, therefore, the greatest discoverer differs only in degree from the most hard working imitator and apprentice, whereas he differs in kind from someone who is gifted by nature for beautiful art. (AA 05: 308-9, section 47) ${ }^{1}$
\end{abstract}

In this picture we have discovery and learning in the sciences and the arising of ideas in the arts. There is a strict separation. But I wonder whether Kant went too far in drawing this distinction and by excluding Newton from the sphere of genius. On the one hand, Kant is right in pointing out that there are definitions, theories, and proofs in the sciences which allow us to learn those sciences step by step, while this cannot be said of the arts. There are no proofs in matters of art. There is no deductive reasoning. But on the other hand, not just anyone can discover definitions, theories, and proofs, and we often say, contrary to what Kant claims, that mathematicians and scientists are geniuses. We say Einstein was a genius. Understanding Einstein's theory and following a proof step by step is one thing (and difficult enough), but discovering the theory and finding the

1 References are to volume and page numbers of the Academie Ausgabe (AA). 
proof oneself is an altogether different matter. Not everyone can be said to be capable of having done what Einstein and Newton did. Why should discovery not be a sign of genius, even if later on others can learn the theory and follow a proof step by step?

Kant writes that poets cannot say how their ideas "arise and come together in their heads". But is this so different in the case of scientists? They have ideas, too, and they usually do not arrive at them in purely deductive ways. ${ }^{2}$

But according to Kant, "even if one thinks and writes for himself, and does not merely take up what others have thought, indeed even if he invents a great deal for art and science, this is still not a proper reason for calling such a great mind [...] a genius" (AA 05: 308, section 47). For Kant, the reason for this is that in the sciences there is some kind of "natural path" of discovery, whereas in the arts there is no such path. Thus he goes on to say that "just this sort of thing could also have been learned and thus still lies on the natural path of inquiry and reflection in accordance with rules" ( AA 05: 308, section 47, italics mine). I have doubts about this, and in the following I will repeatedly come back to this point.

It is true that there is objectivity and progress in the sciences in ways that cannot be found in the arts and that one is therefore led to speak of a "natural path of inquiry and reflection in accordance with rules" (auf dem natürlichen Wege des Forschens und Nachdenkens nach Regeln). Kant even thinks that this path is unique, as if there were no other one possible. He writes "auf dem natürlichen Weg" and not "auf einem natürlichen Weg". For him there is only one. But I wonder whether this path is indeed that "natural" and unique as Kant thinks it is. Contrary to what Kant claims, it seems to me that when we move into more abstract mathematics, there is much freedom in how we can set up definitions and even whole theories. Alternative theories and alternative proofs are possible. Starting from the natural numbers, we can move to the rational, the real, and the complex numbers, each extending the previous one. But we can also, alternatively, move into very different kinds of number systems. Starting from the nat-

2 Of course I am not the first one to find Kant's claims and arguments not convincing here. Thus Donald W. Crawford already writes: "I have no confidence that mathematicians can tell us how they know how to begin an unobvious proof or construction any better than Homer and Wieland could have told us how their ideas came together in their heads" (Crawford 1982, p. 166). He criticizes Kant's arguments by observing: "And this surely is a confusion between the order of discovery (ordo inveniendi or ordo cognoscendi) and the order of teaching or systematic exposition of truth already discovered (ordo docendi)." (p. 165) Already Aristotle was aware of the fact that proofs are often written down (deductively) in the opposite way compared to how they were discovered (inductively and intuitively). 
ural numbers, instead of adding new numbers, we can systematically identify certain numbers with each other. We can choose a prime number, say 7 , and identify each number $n$ with the numbers $n+7, n+14, n+21, n+28$, etc. This is an alternate. From here you cannot extend to the complex numbers any more. You either go this way, or you go the other way.

We can also adopt abstract axiomatic theories of so-called number "fields", which includes the complex numbers as well as the strange case involving the number 7 indicated above. Here we can have "algebraic" numbers of "positive characteristics". In such fields it might happen that adding the unit 1 several times to itself will give zero (as in the case with the number 7): $1+1+\ldots+1=0$, or (if we loosen the requirements for a field a little) that usual and commonsensical rules such as $a b=b a$ or $a(b c)=(a b) c$ no longer hold. These are strange "numbers". It took mathematicians some time to accept what we now call the "complex numbers" as the "natural" extension of the real numbers. I think there are good reasons for saying that there is not only discovery but also invention involved in mathematics. Even if we say that mathematics is already out there in a Platonic realm of ideas, or in a Fregean third realm of thoughts, waiting to be discovered, I think it matters what we see and cut out from this realm. This is an idea I want to explore in this essay. It simply matters to us (what theory we have), and it seems to me that Kant is downplaying, or not sufficiently aware of this part: the seeing and cutting. This is more than discovery. It involves intuition and making choices.

Differential and algebraic geometry are very complicated and rich theories that lead to many questions which we have not answered yet, and it does not seem obvious to me that there is only one way in which these theories will be developed in the future. Regarding physics, I wonder whether relativity and quantum theory lie on "the natural path". Nor is it clear to me that they do so "in accordance with rules". What exactly should those rules be? Would they be methodological meta-rules of enquiry? Would they be rules of mathematics proper? Are there rules that tell us which rules we should adopt? What are the rules that make us think of a "natural path", or even "the" natural path?

Usually it is the case that rules surface only post factum, such as the axioms of what we now call "fields" and of which the real and the complex numbers are special cases. Who knows what else is swimming under that surface? Is there only one, single path of investigation and development? How about statistics, probability, methods of approximation, and the use of computers? How much of which field of mathematics will be developed and practiced? What will surface? Everything? Social, economic, political, and many other factors that are contingent from the point of view of mathematics proper come into play here. There are different styles of practicing mathematics, and different styles make 
for different paths. Different paths lead to different theories, and different theories are the objects for the next generation of researchers to work on. It seems to me there is no single path, neither regarding method nor regarding result. We are not aware of what has not surfaced and what we left at the side. There are choices involved in the production and construction of theories, and these choices will be imbedded in those theories even if they will be forgotten as such. We often get used to what we have and then think of it as the only possibility. But sets of accepted ways of reasoning keep changing. So do sets of accepted proofs, practices, styles, and the questions mathematical communities consider worth asking (see Kitcher, pp. 149-271).

One basic difference between the arts and the sciences is that in the arts we are dealing with individual works, individual poems, paintings, and musical compositions, whereas in the sciences we are dealing with general and abstract rules and theories. A poem can be repeatedly read and memorized, a painting can be looked at, and a musical composition can be performed and listened to. Works of art are objects of the senses, whereas a scientific theory is something abstract that is applied and not contemplated, so one could argue. It is this aspect of applicability that makes the scientific theory so useful and powerful, one might say. But for poems, paintings, and musical compositions there are no such applications. They are individual works of art to be cherished for what they are in themselves. They are objects of the senses and are supposed to speak for themselves. Thus individuality, sensibility, empirical factors, and contingency play a role in the arts and not in mathematics, so it seems. Mathematics is universal and a priori. I do not want to challenge this universality and a priority. But I wish to challenge the idea that it is only those very objects we have in our mathematical theories now that are possible. I want to show that there are other mathematical objects and theories that are possible as well, but have not been discovered and maybe never will be talked about. There are other "natural" paths.

If we do not think about aspects of application and focus instead on the scientific theories themselves, as ends sought for their own sake (as scientists often do), the distinction between the arts and the sciences becomes blurred. Pure mathematics is usually done for its own sake, comparable to how art is done for art's sake, l'art pour l'art. A mathematician can work and live in his or her world of abstract ideas and problems, comparable to how Vincent van Gogh lived in his world of colors, shades, and shapes and light in nature and in his paintings. Both see the world in unique and individual ways, and it will take time for others to see what they saw. Mathematicians and painters can set new standards. Both can be diligent and work to exhaustion and even insanity. The great discoveries in the sciences were not completely guided by rules. Con- 
trary to what Kant claims, they were not simply lying on "the natural path of inquiry and reflection in accordance with rules". I think there is no such path.

There are many different possible criteria of what we want, or might want, criteria of usefulness that depend - in addition to criteria of truth - on aesthetic, economic, political, and other factors. These factors do not determine what is true, but they affect our interests. They affect where we look and what we keep and value as part of our new theories. What we discover depends on our choices regarding which axioms to adopt and which theories to develop. If we go this way, we will discover $X$. If we go that way we will discover Y. Once you embark on $\mathrm{X}$, you might never see $\mathrm{Y}$. One might say that this does not matter, because mathematical theories are already out there, in a Platonic realm, waiting to be discovered. But then I could say the same about all poems, written and unwritten. I could say that they too existed already in some Platonic realm. Hence discoveries in mathematics are not completely different from creations of works of art. They are creations and inventions, too, as the latter can also be seen as discoveries.

It thus seems to me that the difference between mathematics and the arts is not as radical as Kant depicts it to be. Let us look at the idea of extension and development again. Einstein broke with Newtonian physics. He was guided by some classical ideas (indeed "in accordance with rules"), but he also did not follow all of them. He broke some of those rules (not "in accordance with rules", contrary to what Kant claimed). Here mathematics can be compared with the arts. Artists work within traditions, but they also break with these traditions. They create and initiate new movements. Kant says that "no Homer or Wieland can indicate how his ideas ... arise and come together in his head, because he himself does not know it and thus cannot teach it to anyone else either". But could Newton or Einstein do this? Could they "indicate" much better than Homer and Wieland how they arrived at their ideas in the natural sciences? Better yes, but completely? Does discovery not take inspiration, too? Does it not take "Einfalle", as one says in German, that is, sudden "intrusions" and "impacts" from the outside, from outside the field of study itself? This aspect of an "outside" is, I think, what contradicts Kant's idea of a "natural path". The outside can later become part of the inside, part of the mathematics we now have. What was accidental has led to something that now seems natural and the only possible way.

It is true that once we have familiarized ourselves with the definitions and basic theorems of a theory or practice, we will be able to follow a proof step by step. But even then we cannot immediately see, at each step of the proof, why we should do this and not that. Following is not the same as understanding and doing it oneself. Let us look more closely at the differences. Why should we 
at this point in the proof apply this theorem and not another? Why should we, at this point, set $x=3$ and not $x=5$ or 119 or any other number? In the course of a single proof many choices are made, choices among already established theorems and choices among infinitely many possible applications (what to apply a theorem to). These choices are not dictated by the definitions and theorems themselves. That is why proofs are so hard to find. I think it is for this reason that also Newton and Einstein cannot teach us what they did and how their ideas "arise and come together" in their heads. They themselves do not know it. ${ }^{3}$

Only when we see the result of the proof as a whole, at the end and in retrospect, after having gone through the proof many times, will it appear to us as if it were all natural and lying along a "natural path". Only then will it seem to us as if there were only one possible path. But this is wrong. Later on, others will find shorter proofs. They will find other "natural paths" that lead to the same result or a more general one. If the latter happens, the whole picture will change. This might even lead us to change some of our assumptions. A change of perspective can go all the way down to the basics. To put it into more general terms: The mind affects what we see - not the things themselves, but their appearances (and this is all we have). The fact that certain things appear and others don't has to do with us.

I think Kant could have stressed and further developed the aspect of originality and creativity in mathematics by referring to his analytic-synthetic distinction and his view that mathematical propositions are synthetic and not analytic. Synthesis allows for imagination and intuition to play more substantial roles. But Kant did not do this. He did not go this way. For him, when it comes to math-

3 Henri Poincare (1854-1912) defended the relevance of invention and intuition in mathematics. As there are logical-analytical minds (analyste), so there are geometric-synthetic-intuitive minds (géomètre), he says. Knowing the rules is not enough, and this is similar to how we play chess: "de tous ces chemins, quel est celui qui nous mènera le plus promptement au but? Qui nous dira lequel il faut choisir? Il nous faut une faculté qui nous fasse voir le but de loin, et, cette faculté, c'est l'intuition. Elle est nécessaire à l'explorateur pour choisir sa route, elle ne l'est pas moins à celui qui marche sur ses traces et qui veut savoir pourquoi il l'a choisie" (p. 36); "l'intuition est linstrument de linvention" (p. 37). It is the end that justifies the "why" (pourquoi). Poincare is sympathetic to Kant's notion of intuition (Anschauung) as well as his idea of the synthetic a priori. Also Charles Parsons has argued for the necessity of Kantian intuition in mathematics. But Parsons focuses more on the role that intuition (Anschauung) plays in our constructing mathematical objects (following the idea that concepts without intuition are blind) and he focuses less on the aspect of intuition in the choices and value judgments we make (intuitive discovery, German Intuition, not German Anschauung). Charles Parsons focuses more on the object, whereas I here focus more on the method and the fact that different methods lead to different objects. 
ematics, intuition and imagination were merely subservient to rules of the understanding. Although we need intuition and imagination to carry out proofs, they do not contribute something on their own. It is this last point that I wish to question.

Let us return to the distinction between singularity and generality. The arts give us single, individual works of art, and the sciences offer general theories. Art is appreciated and contemplated, whereas the sciences and their theories are applied. For Kant, mathematical and scientific theories consist of rules. At one point he even says that "mathematics is nothing but rules" (Reflection 922, AA 15: 401). Once we understand the rules, we can apply them and they seem to determine everything. In Kant's picture, they put us on firm and fixed rails, whereas works of art do not function in this way. Indeed, instead of speaking of applications, we say that works of art "speak for themselves" and unfold worlds of their own. They are full of surprises. Kant says artists produce "models" (Muster) which other artists imitate (Nachahmung, AA 05: 309) in order to become original artists themselves. They do not just copy (Nachmachung, AA 05: 309). Works of art are exemplars and not rules, even if they seem to be "an example of a universal rule that we are unable to state". But I think this distinction can become blurred when we look more closely. On the one hand, students of mathematics and physics can try to understand scientific theories by trying to find proofs themselves. They can think ahead and then come up with new proofs. They do not blindly and mechanically apply old rules. In doing this they are usually guided by their favorite examples and their individual interests and backgrounds. Thus the individual perspectives of mathematicians do matter to what is and what is not discovered. On the other hand, art sometimes is mechanically reproduced and applied, for instance in advertisement and products of mass-consumption, for instance CDs, perfumes, posters, clothes, cars, motorcycles, etc. The line between mechanical Nachmachung and creative $\mathrm{Na}$ chahmung in the arts is not clear-cut. And there is a similarly foggy line within mathematics, namely in our practicing, learning, and doing research in mathematics. How much do we understand ourselves and to what degree are we just blindly following others? If we say we do it "ourselves", who do we think we are? Do we ever really do anything all by ourselves? Wittgenstein has shown us some of the intricacies of such questions in his reflections about drill in mathematics (although I think he went too far). ${ }^{4}$

4 I think he went too far in reducing rule-following to drill and habits, and he went too far in reducing normativity to social and evolutionary factors (see Wenzel 2011, "On Wittgenstein on Certainty"). But how to read Wittgenstein is disputed. Some scholars do not read him as making or suggesting such reductions. 
It should by now be clear that there is something problematic about saying that mathematics is "nothing but rules". Let me focus on the aspects of particularity, individuality, and singularity again. A mathematician who does research often does not work so much with abstract rules but instead has a typical example in mind. Such an example serves as a model that allows him to see certain essential features concretely, so that he can manipulate and modify these features to better suit the problem he is trying to solve. If one understands one or two cases very well, one has a good handle on the whole theory. Mathematicians who do research know this well. One often goes by examples when doing research, because there one can "see" what is going on when one changes some parameters or some basic assumptions while keeping others fixed. One can see what will happen if one twists those exemplary models a little here or there to suit or challenge the problem at hand. In this way such models can serve as "models of imitation" and models of modification, similar to exemplars in art. A crucial point in this is their concreteness and particularity, because it is this concreteness that allows one to see more than what is implied by the general and abstract nules alone.

I do exactly that when I work for instance on linear algebraic groups in general by having the particular group $S L_{3}$ in mind. The group $S L_{3}$ has properties a group in general does not have. It is by focusing on the particular example and model $S L_{3}$ in its concreteness (which is more specific than the theory in general and thereby goes beyond that theory) that new ideas and insights often arise. Aspects from "outside" (not within the general theory) thus can come in. This can even lead one to change some of the rules one started out with. One can change axioms or assumptions of the framework, or even change the framework itself. In that sense researchers often work like artists. They sometimes follow concrete models and not abstract rules. Thus Kant's own theory of genius and the arts could have led him to see such aspects of creativity in mathematics, had he only paid more attention to what is actually going on in learning and doing research in mathematics. I think it would have been more obvious to him, had he been more interested in the higher mathematics of his day, such as infinitesimal calculus, as Hegel was, or in learning mathematics as Wittgenstein was interested in. It will be more difficult (but not impossible) to see the aspects I want to bring out, if one restricts one's attention to triangles and 5+7=12 as Kant more or less did.

Kant's exclusion of scientists from the realm of geniuses (AA: 05:308-9,section 47) occurred in the development of his general theory of genius. He famously says, "Genius is the talent (natural gift) that gives the rule to art. [...] Genius is the inborn predisposition of the mind (ingenium) through which nature gives the rule to art" (AA: 05:307, section 46). He thinks that it is "through" Homer and his 
genius that nature gives the rules of epic poetry to art, whereas Newton did it himself, through his own diligence, and we all could do it if we were only diligent enough. Homer therefore cannot explain what he did, but Newton can. Kant of course has a point. There is more freedom in the composition of a poem than in the development of a proof. One can change words here and there and still have an epic poem, whereas if one changes formulas in a proof one might end up not having any proof of anything anymore. The proof will suddenly not work and be invalid, having zero value. Mathematical proofs are strict in that sense.

But in spite of this strictness, proofs can also change. If a proof is as long as the Odyssey, one will easily get lost and reading and following will become an odyssey itself. Later a shorter proof will usually be found, and then one sees that there was more than one way "the" proof could go. Newton will therefore be hard pressed to explain every step. He actually cannot. The reason is that there is actually no necessity in those steps. There is no necessity in why this theorem is applied here and not another, why it is applied in this way and not another, why I refer back to that previous result and not another. It is I - the reader, or whoever carries out the proof - who does the choosing and referring. The necessity is only in the "if-then", not in the "if" part. Nor is there any necessity in where in the proof the "if" part occurs. If you apply this theorem here in this way, such and such will necessarily follow. But if you do not apply it, nothing will happen; and if you apply another theorem, something else will happen. Other proofs are always possible. Even the whole Newtonian theory, the framework within which a proof by Newton is carried out, is not the only possible one. Leibniz had another. There is analysis and there is non-standard analysis. There is Euclidean geometry, and there are non-Euclidean geometries. There are fields of characteristic zero, and there are fields of positive characteristic $p$. There is plenty to choose from. There are alternatives. It is not a one-way road. Sometimes things are going the other way, and there are junctions. Even within a fixed framework there is much to explore and much to choose.

Thus, contrary to Kant, there is no unique and "natural path of inquiry" (309). There is lack of necessity at least at two levels, regarding theories chosen and regarding steps taken within those theories. Theories keep developing and changing. Leibniz offered an alternative way, and Weierstraß, Riemann, and Einstein later on had altogether new ideas. Kant talks of reflection and inquiry "in accordance with rules", but it seems to me these rules are not prescribed. They did not fall from the heavens. Peano said that the natural numbers are given by God, but the rest is done by us (as far as mathematics is concerned). Higher mathematics is more than just the set of natural numbers with addition. The rules of any advanced mathematical theory are not as predetermined as Kant 
takes them to be. We can change them and pick others. Even if mathematics appears to be "nothing but rules" in the "if-then" sense, we can still ask: Which rules? And when and where are they used for what? Hence we can ask: Which mathematics? It seems to me that Kant's arguments for the exclusion of mathematics and the sciences from the domain of genius do not sufficiently take into consideration our actually doing mathematics.

This is not only a psychological factor. Our doing research has lead to the mathematics we now have, and we could have developed another. I don't want to say that $2+3$ could be 0 in our ordinary sense of natural numbers. But if you work over fields in characteristic 5 , this is what will happen. There you write and think $2+3=0$. If you work with the real numbers, you take it for granted that $a b=b a$; but if you work with matrices, you will not. The rules depend on objects and theories, and it is our choice what objects and theories to work with. There are undiscovered theories and roads not taken, just as there are poems not written. Although mathematics is not the same as poetry or painting, and although there are differences, it seems to me these differences are more a matter of degree and not as absolute as Kant thought.

\section{Imagination}

Kant claimed that mathematics is "nothing but rules" and (for this reason I think) he excluded it from the realm of genius and beauty. Nevertheless, I think Kant had all the tools at his disposal to do otherwise. He had a rich theory of schematism and imagination, which would have allowed him to explain aspects not only of construction, but also of invention, genius, and beauty in mathematics. In addition to this, his regarding mathematics as essentially synthetic would have invited such explanations. This applies especially to our ways of actually doing mathematics, learning, and doing research in higher mathematics. In the following I will try to use some of Kant's insights into the nature of imagination and some of his ideas about schematism to reveal such aspects.

In the first Critique sensibility and understanding are established as the two pillars of human cognition. They give us intuitions and concepts. How exactly they depend on each other and "cooperate" has been a question of discussion and controversy ever since Kant. According to him, intuitions without concepts are "blind". But if we want to say that infants and animals are not blind, should we then have to say that they already have concepts, or at least the categories? Infants develop conceptual capacities, but most animals never do. Does Kant's conception of 'transcendental synthetic unity of apperception' apply to them? And, to approach the question from the other end (on the line from animals 
to infants and fully grown up humans), do we adult human beings always think when we perceive? Do we need concepts and language in our every-day perceptions? Or is there some kind of non-conceptual, pre-conceptual, or pre-predicative perception, some kind of vorprädikative Wahrnehmung (Husserl)? Is there some kind of "simple seeing" (Fred Dretske - to name just one analytic philosopher who takes this view)? Is there some pre-conceptual but nevertheless meaningful and not blind experience when we don't pay attention, day dream, doze off, or gradually wake up in the morning not knowing whether we are awake or dreaming (Hermann Schmitz)? These are questions that have been much discussed in attempts to clarify the interplay between perception and conception in the light of theories of vision, evolution, and cognitive science. They are discussed in our trying to specify what is distinctive about us human beings in comparison with other, non-human animals.

Are we just another kind of animal? Or are we special creatures that should not be called "animals" at all? In the Greek tradition we are animals that have

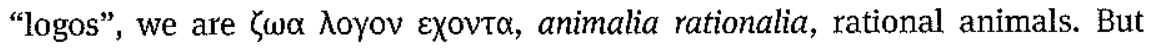
what exactly "rationality" is supposed to be is disputed. Biologically there seems to be continuity through and throughout evolution. But biology offers only one perspective. Linguistics, anthropology, and philosophy offer other views.

In Kant's philosophy, imagination serves as a link between sensibility and understanding. The categories of the understanding are schematized in modes of time and space in their applications to sensible intuitions. Kant is interested in justification, not in genesis and development. But a separating line is still difficult to draw. He saw the relevance of imagination in his theory of threefold synthesis and in his deduction of the categories in connection with consciousness and the unity of apperception. But the line between empirical and transcendental aspects is not clear. Nor is the role of imagination. How "spontaneous" and how independent imagination is from the power of the understanding is a delicate question. How free is imagination from rules? What exactly are rules? These questions are not idiosyncratic to the Kantian system. When suitably translated, they arise in current philosophical discussions of cognitive science and theories of vision. They appear also in current discussions of internalism versus externalism in regard to meaning and perceptual content. John McDowell claims that concepts go "all the way out", contrary to Gareth Evan's views (see Wenzel 2005). Hilary Putnam's doubts that meanings are "in the head", and his arguments have been extended by Tyler Burge to issues about perception and perceptual content. Meaning involves not only concepts but also the environment, physical and social. Perception thus involves capacities comparable 
to Kantian intuition and imagination. The terminology is new, but many of the problems are old.

The general question of how independent imagination is from the understanding can be asked particularly with respect to mathematical objects. We need intuition and imagination to draw lines in space. We need them to carry out proofs in geometry, and we also need them to conceive of numbers in successive synthesis in arithmetic (see the work of Charles Parsons). For Kant the two sides of the equation $5+7=12$ are different due to their intensions, not their extensions (Iseli p. 90). They are different in content, because they were arrived at in different constructive ways, and these ways require intuition and imagination (Wenzel 2011, “Urteil" p. 2288). The equation is true for synthetic and not analytic reasons. Kant's views are non-standard, even for his own time, and they depend on his understanding of time and space as being "subjective" in the framework of his transcendental philosophy. Frege distinguished between "sense" (Sinn) and "reference" (Bedeutung) to explain the truth and nontriviality of an equation such as $5+7=12$. But for him it was more reference and extension that matter, and less sense or intension (not to speak of intention). Even though he speaks of "sense", this notion is similar to the notion of reference. Husserl held on to another aspect of "sense". For Frege, sense is purely objective, to be found in the third realm, timeless and to be grasped. Sense is not made. He does not pursue a theory similar to Husserl's intentionality and noem $a$, and he does not accept the Kantian notion of intuition or the framework of transcendental philosophy either.

In the third Critique, imagination takes a much more central role than in the first, which is no wonder because judgments of taste allow imagination to be free from rules of the understanding and to make substantial contributions (in the free play of imagination and understanding and the pleasure it gives rise to). In judgments of cognition imagination does not have this kind of freedom and does not make this kind of contribution, neither in empirical nor in pure and mathematical matters. Unfortunately, for Kant mathematics drops completely out of the picture in this new, aesthetic context of the third Critique. Mathematics cannot be beautiful, Kant claims, contrary to what he had said in his earlier writings (before the mid $1780 \mathrm{~s}$, see Wenzel 2001). Yet Kant does not view this as unfortunate. He thought so highly of mathematics that he wanted to save it from fashionable and unstable ways of thinking and mere talking. For him, mathematics and the mathematical sciences were fortunately saved from wild speculations and from people who do not know what they are talking about (Wenzel 2001). In this Kant had a point. But I think he could have instead, or in addition, used his theory of free play between imagination and understanding to find out more about how mathematics is actually done and what its nature actually is. His in- 
sights into the loose interplay between imagination and understanding and the aesthetic playfulness of their interaction, when each plays, so to speak, with the function of the other, are after all rich insights.

In doing mathematics we often go by examples. We use them as models and do so in analogical ways when looking at new objects, problems, and open questions. Under the influence of John Locke and Alexander Baumgarten, Kant was aware of this aspect (Koriako, pp. 156-61). But he could have developed it further than he actually did. We are often dealing with particular instances, looking for suitable rules, and then use reflective judgment (reflektierende Urteilskraft), i.e., the power of judgment in its reflective function. The object at hand might call for new rules and a new framework. Familiarity with rules is necessary but not always determining. Although we often do mathematics mechanically and "blindly", as Wittgenstein said, we do not always do it in this way. We are never completely blind. Learning is more than drill (Abrichtung). Doing mathematics is more than carrying out mechanical calculations to get the bill right. We sometimes play with rules and instances. We try out new things. Learning mathematics and doing research are done in ways that go beyond mechanisms and rule-determined behavior, and I think this does matter to the development of mathematics and therefore in the end to mathematics itself (what mathematics we end up having). Children and researchers make use of playful features when speculating about the applicability and suitability of rules. This is more than mechanical and blind trial and error. We use examples we already know and we use them in analogical and ingenious ways.

In doing mathematics we are neither blind as Wittgenstein portrays it, nor are we determined as Kant thinks. Mathematics is not as fixed as Kant tends to think it is. Had he been more aware of the factors of interest, change, indeterminacy, and creativity, I think his theory of free play in aesthetic judgments would have allowed him to make interesting contributions to the nature of mathematics.

Imagine you work with the real numbers and think about an equation that has no solution in this number field, such as $x^{2}+1=0$. You think about somehow extending this field in order to have solutions for the equation at hand. You start with the real numbers and imagine ways of introducing new numbers. In contemporary mathematics we have the complex numbers, a number field that is an extension of the real numbers. There are different ways of introducing these numbers, relying on new notations (when a complex number is represented as an ordered pair of real numbers), or relying on geometry (when a complex number is represented as a point, or vector, in a two dimensional plane). The resulting structures are isomorphic, and happily in this new field every polynomial equation has a solution, which is what we were looking for. The complex num- 
bers are what we call "algebraically closed". But something had to be given up. The real numbers are "ordered". They can be represented along a straight line, with negative numbers on the left and positive numbers on the right, such that the ordering respects addition and multiplication (sums and products of positive numbers are again positive numbers, that is, if $x<y$ and $y<z$, then $x<z$, and if $x<y$ and $z>0$, then $x z<y z$; see Lang, p. 390). But no such ordering is possible for the complex numbers. Thus if we originally assumed that ordering was essential for numbers, we now either have to say that the complex numbers are not numbers any more, or we have to drop this assumption. Mathematicians have chosen the latter way. The complex numbers are now considered to be "numbers", not the real numbers, but still really numbers. The axioms we now have for number fields usually do not include well-ordering. We cannot have everything. If we ask for a further extension, beyond the complex numbers, further assumptions will have to be given up. The so-called "quaternions" are an extension of the complex numbers and they can be realized in four-dimensional space over the real numbers, but now the axiom of commutativity has to be given up. For quaternions it is no longer true in general that $a b=b a$. Should we then still call them "numbers"? Well, this is up to us again. Of course one might say all that this does not matter to mathematics itself, that this is all only about names and words. But I am trying to show that it matters whether we use this mathematics (writing textbooks focusing on the complex numbers) or that one (writing text books focusing on the real numbers, or the quaternions). It matters what we use. It matters regarding where we go and where we end up.

When learning or doing research, on the one hand imagination plays with various possible functions of the understanding when asking for suitable concepts and rules. On the other hand understanding guides our way of looking at the case at hand and demands from imagination to fill in and to create what the rules require. Methods of trial and error are used and often pleasure arises. I think more than pleasure in success is involved here. ${ }^{5}$ I think the pleasure involved in doing mathematics can also be pleasure in the play itself. Even if playful attempts or acts of contemplation do not yield the desired result, we still

5 The pre-critical Kant could still say "demonstrations in geometry can be beautiful [Schönheit haben] due to their shortness [Kürze], their completeness [Vollständigkeit], their natural light [natürliches Licht], and their suitability [leichte Faßlichkeit] for an easier understanding" (Anthropology Lecture Collins 1772/73, AA 25: 177; translation mine, see Wenzel 2001, p. 417). The Kant of the Third Critique does not think like this any more. "Shortness" and "completeness" now are too objective. Ideas of "natural light" and "suitability" drop out. Maybe "natural light" is too poetic and "suitability" too much in the spirit of transcendental realism (which assumes that mathematics is out there, independently of our minds). 
can feel the pleasure of adventure in trying out new things, new objects and new methods of learning that lead to new objects. The search itself has a value and I think the aesthetic aspects involved also matter to mathematics itself, because, again, they influence how and where we look and thus they matter to the question of what we find, accept, and choose to use - and thus now have.

One might still argue that such pleasure is not part of mathematics proper and that when playing with rules and instances one is not strictly speaking "doing mathematics" any more. In this view, only when it comes to the proofs, in the end, is one doing mathematics again. But I would counter such a view by pointing out that the results of playful considerations are often the new objects and that therefore the play itself matters. It literally does mattor, because it leads to new objects, i.e. the subject matter for mathematical understanding. New methods can be agreed upon and then become part of the growing corpus of mathematical knowledge. Besides political, economic, geographic, and many other influences, there are also aesthetic influences that matter in the development of mathematics. They matter not as necessary means but as decisive factors.

Kant had an aesthetics theory according to which judgments of taste can be pure and $a$ priori. Purity consists in disinterestedness regarding the existence of the object. We do not depend on the real existence of the object as we find it in the case of satisfaction for the agreeable (when the object affects us and our senses and sensory inclinations are involved), nor do we depend on it as is the case regarding satisfaction for the good (when a morally good action has to be produced or when something empirical is instrumentally good for something else). This freedom of interest, which Kant emphasizes in the first moment of taste, does actually suited mathematical objects. We do not depend on their existence regarding our sensation, and we do not need to bring them into existence. They are freely available for everyone. Furthermore, the a priori justifying ground, which Kant had found to underlie aesthetic judgments (subjective purposiveness), does suit mathematics, because mathematical objects can show new and unexpected features. One might argue that the purposiveness we meet with here tends to be objective purposiveness (between objects) and not subjective purposiveness (between the object and our subjective state of mind). But as I have shown above, it seems to me that the latter are involved as well.

In everyday life, imagination is necessary when we recall an object that is absent, when we recall a melody, or the face of a friend. Both reproductive and productive functions are then essential, as Kant has pointed out in the A-version of the Deduction of the categories. In the $20^{\text {th }}$ century, studies of perception have shown that these functions of the imagination are also involved in real per- 
ception, when the object is actually present and we are not just imagining our remembering things. Also in real perception it is the case that we do not actually see everything we think we see. We literally think more than we see: We project and fill in a good deal in more or less conceptual ways. We rely on memory and expectation, invention and imagination. We take much for granted also in perception of real objects, and we do so by using imagination. Kant had a good idea of this when he saw in the imagination "a blind though indispensable function of the soul" (Critique of Pure Reason, section 10, A78/B104). But he did not develop this idea in his views on mathematics.

Some of Kant's observations about imagination do apply to mathematics as well, because also - and particularly - in mathematics we can ask how "absent" or "present" an object is. Imagination is productive (exhibition originaria) with respect to intuition in time and space, a priori and empirically, when we draw a line in our mind or on a piece of paper. Imagination is necessary to give us pure intuitions (Anschauungen) in mathematics. In order to think of a line or a triangle, we need to imagine them as drawn and constructed and as given totalities. We give it to ourselves. Imagination is necessary in order to give substance to abstract mathematical reasoning. Intuitions have to be built up, manifolds have to be synthesized and held together. Only then do our concepts have objects. Only then do our thoughts have substance to which they can be applied. We think of, and also somehow "see", a complex number, a continuous but nowhere differentiable function, or a linear algebraic group that is locally eight-dimensional over the complex numbers. Or should we rather say that we do not see anything at all in such cases and that mathematics is, as Kant claims, "nothing but rules", without any need of intuition? But Kant also famously says that concepts without intuition are empty. Thus we should see something after all. So what is going on?

There is a transcendental function of the imagination to insure unity in apprehension, production, reproduction, and apperception. This basic and productive function is part of imagination in figurative synthesis, and we can turn to this function (Critique of Pure Reason, section 24) to explain that, when considering very abstract and higher-dimensional mathematical objects, we still "see" something and concepts are not empty. But this transcendental function by itself is not enough. There is also productive imagination, which generates methods (schemata) and images (A 140-41/ B 180) that are in called upon in reproductive imagination. Productive and reproductive imagination is intertwined. It is not just all rules. Even chance gets involved, when we do things "spontaneously" in the sense of "unwillkürlich". Kant calls this fantasy (Phantasie). Imagination then is creative, "poetic" (dichtend), and playful: "die Einbildungskraft (als Phantasie) spielt". I think we can be creative and poetic like this while still staying 
within the realm of pure intuition and pure imagination. This activity does not need to be merely transcendental in the sense of being a necessary condition of experience. It goes beyond that, and it does so also in mathematics, because examples, chance, attempts, and analogies are involved, as I have explained above. The activity and its results can still be pure (non-empirical). Kant has argued that there are metaphysical foundations of the natural sciences, and I am here suggesting that there are foundations of mathematics that also involve choice, variation, playfulness, and beauty in mathematics.

Kant does not only have room for, but he also has theories of, pure intuition, exhibitio originaria, and a priori functions of the imagination. The latter don't need to be completely governed by the understanding. Imagination can be productive, and this plays also a role in our doing mathematics, when we use examples and reach out to intuitions that go beyond the rules and concepts we started out with. These examples and models sometimes do not perfectly fall under the relevant rules, and when this happens they will suggest something new. Chance is essential in this, and in doing research we often get new insights from this very surplus, from wrong applications, borderline cases, and Einfälle from somewhere else. We often hold on to concrete examples, schemes, and images, even if they do not perfectly fit the rules and only serve as substitutes. The outer then might become part of the inner.

Through productive imagination and the element of chance we give something to ourselves in intuition. We can thereby experience the surprise of fitting and the encounter of "lawfulness without law" also in non-empirical matters and subjects such as mathematics. We can generate something new, allowing for new choices and new chances, and we can freely recall previous results. This encounter is both active and passive. It is discovery and invention at the same time. It is a form of self-affection, as we find in the enjoyment of playful fantasy when surprise is always around the corner. Through productive imagination we give ourselves pure and "concrete" intuitions in time and space. Think of the Latin root: concrescere, to grow together! We make something pure "grow". It is not the result of processes of abstraction from empirical matters, but it is pure creation. Then we are affected by our own activity and the result of it. This goes beyond the rules of mathematics that we started out with and have used so far. We can produce something new, a surplus, which does not need to accord with those rules.

Besides imagination as it is involved in chance and exemplarity, there is another way in which intuition and imagination do matter. Now I turn to arithmetic. We use symbols in mathematical notation, and good notation is essential in doing mathematics. We need to hold on to something. Reference must be fixed in some way (Wenzel 2010). The question here again is how independent or de- 
pendent, and how essential or inessential, symbolic notation is regarding the rules of our understanding and of mathematics itself. Answering this question will tell us how free imagination can be while still contributing substantially to mathematics.

Kant's notions of figurative synthesis and of monograms involve mathematical and linguistic aspects (see Makkreel, pp. 31-33). In the use of mathematical notation we can see both of them at work. Here we find letters and symbols (the linguistic side) and the meanings they convey (the mathematical side). We manipulate the visible signs and use the result to refer to something in the abstract object again. Kant was aware of this already in 1764 (Makkreel, p. 34).

Kant was also aware of right-left symmetries and problems of conceptually indiscernible differences of non-identical entities (Wenzel 2010). But he thought he could solve these problems with his theory of intuition and mathematical construction. Besides rules, also intuition and imagination are needed in making distinctions. (Kant's way of arguing here again shows the influences from Locke and Baumgarten; see Koriako pp. 156, 166-77). But in all this, for Kant intuition and imagination function only subserviently. In his view, imagination is told by the understanding what to do. As an example of this, let us again look at a mathematical object that was discovered after Kant's time - namely, the complex numbers. Algebra tells us that if there are any square roots of -1 , then there will have to be exactly two of them. Understanding then asks imagination (algebraically so to speak) to fix a referent as one square root of -1 and to fix another referent as the other square root of -1 . We call, or denote them by the symbols, " $i$ " and " $-i$ ". Through rules of the understanding (algebra) we know that there must be two distinct roots, and thanks to intuition and imagination we now actually "have" them. Here imagination and intuition seem to play only subservient roles. It seems to be the understanding that sets the course and that determines what mathematics is. In this way we can understand, retrospectively, why Kant had no room for beauty in mathematics. Imagination did not matter. It had no choice. Hence Kant had no room for a free play of imagination and understanding when dealing with mathematical objects as such. But contrary to Kant, besides the commonsensical views that mathematics can be beautiful and that there are geniuses also in mathematics, a view Kant knew and had previously embraced himself, we now know facts about the nature of mathematics (proper) that Kant did not know and that shake the foundations of his views of mathematics. Since Gödel's 1931 results we know that axiomatic systems can be incomplete. We know that rules do not determine everything. The situation has changed, because on top of the question of which rules or axioms to accept, we now have the additional problem that rules do not settle everything even within their own domains. The questions have become more complicated and pressing. 
Understanding cannot any more be seen as having full control even in matters of mathematics. Intuition and imagination can thus play more than subservient roles, and once imagination's freedom and contribution to mathematics is secured, so is the possibility of a pleasurable and meaningful free play of the faculties that is the ground for beauty and that can lead, by chance, to results that are mathematically relevant. To the newcomer the traces might be lost. But there is always room for new discoveries.

One might still try to drive a wedge between aesthetics and mathematics, arguing that the free play is one thing and its mathematical result is another. But in doing mathematics we go to and fro. We shift from one to the other, between the free play and the result, the example and the rule, intuition and logic, geometry and analysis (compare Poincaré on geometrical and analytical minds, Poincaré pp. 27-40). The two are intertwined. The empirical leaves its traces in what is realized from what is a priori possible. As there are prototype-theories of concepts in philosophy and the cognitive sciences, showing that perception and pictures (images) matter for concepts, so I am suggesting that mathematics is not just rules but that it is done with examples in mind and that this plays a role regarding what mathematics we have. Intuition, imagination, and aesthetics have left their traces.

For comments I wish to thank Riccardo Manzotti, Gottfried Gabriel, Sebastian Gardner, Joel Schickel, Kurt Walter Zeidler, and Michael Thompson.

\section{References}

Carmichael, Robert Daniel (1930): The Logic of Discovery, Open Court Publishing Co..

Changeux, Jean-Pierre, and Alain Connes (1989): Matière à pensée, Èditions Odile Jacob.

Changeux, Jean-Pierre, and Paul Ricoeur (1998): Ce qui nous fait penser. La nature et la règle, Éditions Odile Jacob.

Crawford, Donald W. (1982) "Kant's Theory of Creative Imagination", in 1. Cohen and P. Guyer (eds.), Essays in Kant's Aesthetics, University of Chicago Press, pp. 151-178.

Ekeland, Ivar (1984): Le Calcul, L'Imprévu: Les flgures du temps de Kepler à Thom, Editions du Seuil.

Friedman, Michael (1992): Kant and the Exact Sciences, Harvard University Press.

Gabriel, Gottfried (1997): Logik und Rhetorik der Erkenntnis; Zum Verständnis von Wissenschaftlicher und Ästhetischer Weltanschauung, Schöningh.

Gabriel, Gottfried (2011): "Kreatives Denken. Über den 'Geist' in den Naturwissenschaften", in Phantasie und Intuition in Philosophie und Wissenschaft, edited by Gudrun Kühne-Bertram and Hans-Ulrich Lessing, Königshausen \& Neumann, pp. 199-214.

Gibbons, Sarah L. (1994): Kant's Theory of Imagination: Bridging Gaps in Judgement and Experience, Oxford University Press. 
Giordanetti, Piero(1995): "Das Verhältnis von Genie, Künstler und Wissenschaftler in der Kantischen Philosophie. Entwicklungsgeschichtliche Beobachtungen," Kant-Studien 86, pp. 406-30.

Iseli, Rebecca (2001): Kants Philosophie der Mathematik: Rekonstruktion - Kritik Verteidigung, Berner Reihe Philosophischer Studien 27, Verlag Paul Haupt.

Kant, Immanuel (1998): Critique of Pure Reason, translated by Paul Guyer and Allen Wood, Cambridge University Press.

Kant, Immanuel (2000): Critique of the Power of Judgment, translated by Paul Guyer and Eric Matthews, Cambridge University Press.

Kitcher, Philip (1984): The Nature of Mathematical Knowledge, Oxford University Press.

Koriako, Darius (1999): Kants Philosophie der Mathematik: Grundlagen, Voraussetzungen, Probleme, Kant-Forschungen 11, Felix Meiner Verlag.

Lang, Serge (1984): Algebra, Addison-Wesley Publishing.

Makkreel, Rudolf (1999): Imagination and Interpretation in Kant: The Hermeneutical Import of the 'Critique of Judgment', The University of Chicago Press.

Parsons, Charles (1980): "Mathematical Intuition", Proceedings of the Aristotelian Society, ns 80 , pp. $145-68$.

Parsons, Charles (1983): Mathematics in Philosophy. Selected Essays. Cornell University Press.

Parsons, Charles (1992): "The Transcendental Aesthetics", in Paul Guyer, The Cambridge Companion to Kant, Cambridge University Press, pp. 62-100.

Parsons, Charles (1998): "Intuition and the Abstract", in Marcelo Stammı (ed.), Philosophie in synthetischer Hinsicht, Klett-Cotta, pp. 155-187.

Poincaré, Henri (1970): La valeur de la science (first published in 1905), Flammarion.

Resnik, Michael (1997): Mathematics as a Science of Patterns, Oxford University Press.

Wenzel, Christian Helmut (2001): "Beauty, Genius, and Mathematics: Why Did Kant Change His Mind?" In: History of Philosophy Quarterly 18/4, October, pp. 415-32.

Wenzel, Christian Helmut (2005): "Spielen nach Kant die Kategorien schon bei der Wahrnehmung eine Rolle? Peter Rohs und John McDowell", Kant-Studien 96/4, pp. $407-426$.

Wenzel, Christian Helmut (2010): "Frege, the Complex Numbers, and the Identity of Indiscernibles", In: Logique et Analyse volume 53, number 209, March, pp. 51-60.

Wenzel, Christian Helmut (2011): "Urteil". In: Neues Handbuch Philosophischer Grundbegriffe, P. Kolmer and A. Wildfeuer (eds.), Karl Alber Verlag, pp. 2284-2296.

Wenzel, Christian Helmut (2011): "On Wittgenstein on Certainty". In: Epistemology: Contexts, Values, Disagreement, Papers of the $34^{\text {th }}$ International Wittgenstein Symposium, vol. 19 , Kirchberg am Wechsel, Austrian Ludwig Wittgenstein Society, pp. 320-22.

Wenzel, Christian Helmut, "Mathematics and Aesthetics in Kantian Perspectives". In: The Psychology of the Mathematician, Stephen Krantz (ed.), Mathematical Association of America (to appear). 